\title{
Interpretation Reduces Ecological Impacts of Visitors to World Heritage Site
}

Minimal-impact interpretation is widely used to reduce the ecological impacts of visitors to protected areas. We tested whether verbal appeals and/or role-model demonstrations of minimal-impact behavior by a trained guide reduced noise, litter, and trampling impacts on hiking trails in a subtropical rainforest. Interpretation did reduce impacts significantly. Different interpretive techniques were more effective for different impacts. The experimental groups were mature, well-educated professionals; interpretation may differ in effectiveness for different visitors. Interpretation by skilled guides can indeed reduce visitor impacts in protected areas, especially if role modeling is combined with verbal appeals.

\section{INTRODUCTION}

Most protected areas are available for recreation as well as conservation (1). Visitors, however, produce a range of environmental impacts $(2,3)$, and management agencies have to balance social demand to visit parks against the effects of these impacts on the conservation of biodiversity. They use four main approaches: regulations, charges, physical infrastructure, and education or interpretation $(4,5,6)$. Interpretation programs are the cheapest and least socially intrusive approach and are widely used, but it has proven difficult to test whether they actually reduce ecological impacts.

There have been at least 26 attempts to test the outcomes of minimal-impact interpretation programs (7). All but three of these, however $(8,9,10)$, tested changes in visitor knowledge, attitude, or occasionally behavior, rather than changes in actual impacts on the physical or biological environment. The principal difficulty in testing whether a particular program of minimal-impact interpretation causes individual visitors to reduce their ecological impacts has been establishing a reliable experimental design with adequate controls that can be applied to real park visitors. Here we describe tests that overcome these difficulties.

\section{METHODS}

The experimental site is in Lamington National Park in southeast Queensland, Australia_part of the Central Eastern Rainforest Reserves Australia World Heritage Area. The dominant vegetation is subtropical rainforest. The tests were applied to minimal-impact interpretation programs delivered through verbal interpretation by a tour guide to commercial tour clients on $5-\mathrm{km}, 1$ - to 1.5 -hr walks along a formed track within the World Heritage Area. With the assistance of the tour operator, the interpretation programs were modified experimentally so that different groups walking the same route on different days received different minimal-impact interpretation, as described below.

Three parameters were used to measure ecological impacts: noise, litter, and trampling through shortcutting of corners on the hiking track. All of these impacts are ecologically significant in subtropical rainforest ecosystems and are of concern to the protected area management agency $(2,3)$. Shortcutting causes soil erosion and vegetation damage; litter has been responsible for the death of endemic fauna such as satin bower-birds, Ptinilorhynchus violaceus; and noise disturbs a range of bird and mammal species, including the endangered Albert's lyrebird, Menura alberti. Critically, each of these impact parameters could be zeroed before and after each experiment; therefore, each measured impact could be attributed to a particular group and distinguished from those of independent visitors.

To measure shortcutting, the senior author joined each group as a tour participant and covertly counted the number of people who did or did not shortcut each corner in the track. Noise was recorded continuously using a concealed tape recorder, and later coded into 11 categories at 5-s intervals. For analyses, these categories were aggregated into three: loud talking and shouting, quiet talking, and no talking. Since the number of pieces of litter dropped depends on what people happen to be carrying, and hence is difficult to standardize, we assessed litter-related impacts by placing 12 items of litter experimentally at routine points on the track immediately before each group passed by, and then removing them afterwards, noting which pieces had been picked up by the group. The types of litter used were innocuous items that are often encountered in heavily visited areas, such as bottle tops or wrappers from chocolate bars. In making verbal appeals, the guide indicated that he or she had plastic bags with which to collect litter, as well as gloves in case anyone had any aversion to picking up litter or concerns about hygiene.

The five interpretative programs were as follows. In the Control program, guides carried on unrelated conversations with guests, with no reference to the actual site or environment. In the Generic program, guides provided broad natural history information but did not mention impacts. In the Role Model program, guides themselves acted to minimize impacts-by staying on the track, picking up litter, and only talking quietly - but did not say anything about impacts. In the Appeal program, guides explained the types of impacts and their ecological significance, and specifically requested guests to stay on the track, pick up litter, and keep quiet. Finally, the Complete program combined the Role Model and Appeal approaches.

In addition to comparing experimental and control interpretive programs among different tour groups, the experiment incorporated an internal control for noise and litter impacts. The groups routinely halted halfway along the track to rest. This gave the guides the opportunity to deliver appeals to pick up litter with the full attention of the whole group and to commence role modeling. Impacts prior to the delivery of the interpretation program could thus be compared with those following its delivery for the same individual visitors on the same day. A similar internal control was used for noise, but in that case the guides delivered their verbal appeal, or commenced role modeling, at the first convenient opportunity when wildlife was sighted on that walk. The appeal asked guests not to talk loudly. The relative lengths of time before and after the interpretive interventions therefore differed between walks.

The effects of the different interpretive programs and comparisons between sections of the walks were examined using chi-square and odds-ratio tests. 


\begin{tabular}{|c|c|c|c|c|c|c|}
\hline \multirow[b]{2}{*}{ Program } & \multicolumn{2}{|c|}{ Corner A } & \multicolumn{2}{|c|}{ Corner B } & \multicolumn{2}{|c|}{ Corner C } \\
\hline & Cut & Not & Cut & Not & Cut & Not \\
\hline Control & 51 & 0 & 51 & 0 & 51 & 0 \\
\hline Generic & 87 & 0 & 75 & 12 & 79 & 8 \\
\hline Role Model & 94 & 24 & 38 & 65 & 34 & 84 \\
\hline Appeal & 23 & 30 & 4 & 11 & 34 & 19 \\
\hline Complete & 7 & 93 & 5 & 85 & 10 & 90 \\
\hline
\end{tabular}

\section{RESULTS}

Forty-one individual walks were tested, with a total of 449 individual visitors. Experimental walks were excluded from analysis if the guide was unable to deliver the interpretative program as designated (e.g., if one of the guests initiated a discussion of minimal-impact practices at the beginning of the walk).

For shortcutting of corners, a total of 4939 experimental events were observed for 449 individual visitors at 11 corners. Because of the configuration of the track at different corners, only three were routinely shortcut by visitors, so only these three corners provide opportunities to test the effectiveness of the interpretation programs. For each event, there were two possible outcomes: shortcut or not shortcut. Results are summarized in Table 1.

At all three corners tested, there were significant differences in the incidence of shortcutting between groups subject to different interpretive programs ( $\mathrm{p}<0.01$ in each case). At each corner, the Complete program, combining verbal appeals and role modeling, led to the greatest reduction in shortcutting. The relative effectiveness of role modeling and verbal appeals alone, however, differed between corners. Appeals were significantly more effective $(p<0.05)$ at one corner, role modeling was significantly more effective $(p<0.05)$ at another, and there were no significant differences between the two approaches at the third corner. Using odds-ratio tests, the odds of shortcutting by a visitor exposed to both role modeling and a verbal appeal ranged from 3.5 to 9.6 times less than for visitors exposed to only one of these approaches, whichever was more effective. There were no significant differences in shortcutting between visitors exposed to Control or Generic interpretive programs at any of the three corners. For visitors subject to the Generic program, the odds of shortcutting ranged from 5 to 45 times higher than for those exposed to appeals or role modeling, whichever was less effective at the corner concerned, with differences significant at $\mathrm{p}<0.05$ at each corner.

There were no significant differences in the number of pieces of litter picked up by different groups on the sector of the track before they received any interpretation program. In the later section of the track, verbal appeals significantly improved the odds that visitors would pick up litter, but role modeling did not (Table 2). The odds that a visitor subject to verbal appeals would pick up litter were 5.6 times higher $(p<0.05)$ than for those exposed only to role modeling. Role modeling alone did not improve the odds of picking up litter over either the Control or Generic programs; and the Complete program, combining role modeling and verbal appeal, did not improve the odds over the verbal appeal alone. Within the individual walks, the odds of a visitor picking up litter in the second section, after receiving a verbal appeal at the halfway point, were 12 times greater $(\mathrm{p}<$ 0.05 ) than for the first half of the hike, before the appeal was delivered. This applies whether or not the verbal appeal was coupled with role modeling.

As noted earlier, in order to maximize experimental rigor we defined this test parameter as increases in litter picked up, rather
Table 2. Picking up litter.

\begin{tabular}{|c|c|c|c|c|}
\hline \multirow[b]{2}{*}{ Program } & \multicolumn{2}{|c|}{ Pre-interpretation } & \multicolumn{2}{|c|}{ Postinterpretation } \\
\hline & Pick & Left & Pick & Left \\
\hline Control & 2 & 34 & 5 & 30 \\
\hline Generic & 7 & 34 & 10 & 30 \\
\hline Role Model & 5 & 25 & 9 & 21 \\
\hline Appeal & 5 & 24 & 24 & 10 \\
\hline Complete & 8 & 27 & 29 & 7 \\
\hline
\end{tabular}

than decreases in litter dropped. Many experienced wilderness hikers do indeed voluntarily pick up others' litter, so this is not an unrealistic parameter. For less experienced park visitors, however, there may be a significant psychological distinction. Members of a commercial tour group may refrain from discarding litter simply to avoid unfavorable attention from other group members. Picking up litter, however, may also attract attention if others are not doing likewise. An appeal and example from the guide, in this context, may provide clients with implicit social permission for a behavior at which their peers might otherwise look askance. Our results in regard to picking up litter, therefore, may not necessarily apply to not discarding it.

There were 60845 individual 5-s noise records. For analysis, periods when the guides were talking were removed, and the remaining observations were classified into three categories: nobody talking, talking quietly, or talking or shouting loudly.

Over the course of each walk, some groups became gradually louder from beginning to end, perhaps because of increasing socialization. Other groups became gradually quieter from beginning to end, perhaps because of increasing tiredness. Yet other groups showed no significant change in the average volume of conversation during the course of the walk. Both the sound recordings and the senior author's field observations showed that any effects of interpretive interventions by the guides were quite short-lived. If people did lower their voices, it was only for a short period of time. Any effects of the interpretive programs were thus superimposed upon any longerterm trends due to the internal dynamics of the group. We also tested whether larger groups were more (or less) noisy, but found that group size did not influence noisy behavior significantly in these experiments.

To examine the effectiveness of the five interpretive programs in reducing noise, we therefore used two approaches. First, we compared the number of loud and quiet 5-s sound intervals before and after the guide delivered the interpretative program in each walk. Results are shown in Table 3 . For the seven walks in which the guides provided both role modeling and verbal appeal, five showed a highly significant reduction in noise $(\mathrm{p}<0.001)$ after the intervention. For the other four programs, the level of noise increased significantly on some walks and decreased significantly on others. Aggregated across the other four interpretative programs, noise increased significantly in 6 walks, decreased significantly in 11 walks, and did not change in 10 walks. It thus appears that the combination of role modeling and verbal appeals does often reduce noise, but not for all groups.

As a second and more focused approach, we compared only the 2-min segments of time immediately before and immediately after the guides delivered their interpretive programs. These results are also summarized in Table 3 . The verbal appeals and role modeling decreased noise in six of seven walks $(p<0.025)$ when used in combination, but in only three out of seven and four out of seven walks $(\mathrm{p}>0.05)$, respectively, if used independently. Short-term noise decreased in three of the seven walks with the Generic interpretive program, but in five out of 


\begin{tabular}{|c|c|c|c|c|c|c|c|}
\hline \multirow{2}{*}{$\begin{array}{l}\text { Interpretive } \\
\text { Program }\end{array}$} & \multirow[b]{2}{*}{ Walk No. } & \multicolumn{2}{|c|}{ Pre-interpretation } & \multicolumn{2}{|c|}{ Postinterpretation } & \multirow{2}{*}{$\begin{array}{l}\text { Post cf Pre, } \\
\text { 1 whole walk }\end{array}$} & \multirow{2}{*}{$\begin{array}{c}2 \text { min Post } \\
-2 \text { min Pre, Quiet } \\
\end{array}$} \\
\hline & & Quiet $^{2}$ & Loud & Quiet & Loud & & \\
\hline \multirow[t]{6}{*}{ Control } & 5 & 8 & 37 & 422 & 103 & $Q^{\star \star \star}$ & 5 \\
\hline & 6 & 76 & 0 & 469 & 12 & $-n s$ & 0 \\
\hline & 12 & 24 & 21 & 480 & 57 & $Q^{\star \star \star \star}$ & 6 \\
\hline & 13 & 79 & 1 & 449 & 60 & $\mathrm{~L}^{* *}$ & 1 \\
\hline & 22 & 4 & 34 & 239 & 108 & $Q^{\star \star \star \star}$ & 2 \\
\hline & 26 & 71 & 79 & 170 & 186 & $-\mathrm{ns}$ & 10 \\
\hline \multirow[t]{7}{*}{ Generic } & 1 & 18 & 43 & 199 & 176 & $Q^{\star \star \star \star}$ & 8 \\
\hline & 2 & 71 & 16 & 419 & 84 & - ns & 8 \\
\hline & 8 & 22 & 58 & 51 & 423 & $\mathrm{~L}^{* \star *}$ & -3 \\
\hline & 10 & 30 & 50 & 226 & 210 & $Q$ * & 5 \\
\hline & 14 & 30 & 22 & 268 & 154 & $-n s$ & -4 \\
\hline & 18 & 57 & 18 & 294 & 76 & $-n s$ & -3 \\
\hline & 25 & 60 & 28 & 213 & 265 & $\mathrm{~L}^{* \star *}$ & -14 \\
\hline \multirow{7}{*}{ Role Model } & 15 & 95 & 55 & 233 & 94 & - ns & 0 \\
\hline & 17 & 221 & 64 & 104 & 11 & $Q^{* \star}$ & 2 \\
\hline & 23 & 297 & 96 & 176 & 16 & $Q^{* \star *}$ & -4 \\
\hline & 24 & 2 & 25 & 196 & 286 & $Q^{\star \star \star}$ & 4 \\
\hline & 27 & 96 & 16 & 344 & 64 & $-\mathrm{ns}$ & -4 \\
\hline & 32 & 74 & 2 & 461 & 49 & $L^{*}$ & 2 \\
\hline & 35 & 35 & 1 & 260 & 67 & $\bar{L} * *$ & -2 \\
\hline \multirow[t]{7}{*}{ Appeal } & 4 & 196 & 30 & 356 & 9 & $Q^{* \star \star}$ & 0 \\
\hline & 20 & 24 & 2 & 479 & 79 & $-n s$ & 2 \\
\hline & 34 & 70 & 15 & 412 & 40 & $Q^{*}$ & 2 \\
\hline & 36 & 89 & 15 & 368 & 128 & $\mathrm{~L}^{*}$ & -10 \\
\hline & 39 & 73 & 12 & 358 & 37 & $-n s$ & 2 \\
\hline & 40 & 26 & 149 & 205 & 112 & $Q^{* \star \star}$ & 15 \\
\hline & 41 & 80 & 12 & 349 & 89 & - ns & 0 \\
\hline \multirow[t]{7}{*}{ Complete } & 16 & 93 & 9 & 444 & 36 & $-n s$ & 5 \\
\hline & 19 & 86 & 6 & 469 & 52 & $-n s$ & 1 \\
\hline & 21 & 174 & 74 & 388 & 3 & $Q^{* \star \star}$ & 4 \\
\hline & 29 & 36 & 42 & 249 & 53 & $\mathrm{Q}^{* \star *}$ & 3 \\
\hline & 30 & 13 & 65 & 239 & 178 & $Q^{\star \star \star *}$ & 0 \\
\hline & 37 & 26 & 37 & 319 & 107 & $\mathrm{Q}^{\star \star \star \star}$ & 9 \\
\hline & 38 & 73 & 31 & 362 & 74 & $\mathrm{Q}^{\star \star \star \star}$ & 6 \\
\hline
\end{tabular}

six of those with the Control program. This suggests that the short-term results for the Complete program, as reported above, should be treated with caution.

\section{DISCUSSION}

Of the 26 previous studies, "only two studies investigated the efficacy of educational messages in improving resource conditions" (7). Small brochures handed out by park rangers, with or without verbal appeals, reduced the amount of damage to trees by campers in search of firewood (8), and interpretive signs including minimal-impact appeals reduced damage to rock cairns marking hiking trails (9). One further study, not referred to in the terrestrial review (7), showed that predive briefings reduced the number of coral branches broken by divers (10).

The experiments described here demonstrate that minimalimpact interpretation can indeed reduce a range of actual ecological impacts by park visitors; but there are several caveats. First, the visitors were guests at a lodge that caters principally to relatively well-off, educated, and environmentally aware clients. These results would not necessarily apply to other types of visitors, such as school children or social clubs. Second, the minimal-impact information was provided in person by experienced guides skilled in interpretation. These results would not necessarily apply to information provided solely through signs or brochures. Third, minimal-impact interpretation is more efficient in reducing some impacts than others. And finally, different interpretive techniques are more or less effective in reducing different types of impact. It would thus be valuable to repeat these or similar tests for different types of visitors, different types of activities, and different types of minimal-impact interpretation.
There have been extensive theoretical debates over the psychological mechanisms by which new information may influence the knowledge, attitudes, and behavior of different individuals, including visitors to protected areas $(11,12)$. In particular, this debate has contrasted more direct and conscious mechanisms with those that are more indirect and subliminal $(13,14)$. The experiments described here did not aim to distinguish among these types of mechanisms, nor did they rely on any particular educational theory or psychological mechanism. By measuring reductions in environmental impacts, they tested the outcomes of behavioral change associated with a particular interpretive program. The results hold for these specific interpretive techniques whether or not they are justified by educational theory.

The particular design and components of the interpretive programs used for these tests, however, are derived from the currently accepted best practice in parks and ecotourism interpretation $(1,5,6,7)$. The best practice, in this context, has not been determined by measured effectiveness in reducing impacts, since such measurements have not previously been available; instead, it may reflect the informal observations of individual guides, although it is also influenced at least partly by educational theories $(6,7,11)$. In line with approaches taken by parks agencies, the interpretive components distinguished in these tests reflect a view that tourists respond to interpretive information in a rational manner. Thus, for example, we distinguished information, role modeling and verbal appeals, but we aggregated results associated with different individual guides.

It is equally possible, however, that the attention that individual tourists pay to the guides and their conscientiousness in following the guides' instructions is influenced not so much 
by interpretive content and delivery mode, but by how much each tourist is attracted to, and wants to impress, the guide concerned. This might well be the null hypothesis adopted, for example, by researchers with backgrounds in sales or marketing. As well as repeating these tests for different types of client, activity, and information delivery, therefore, it may also be valuable to compare tourist responses to guides of different age, sex, appearance, and demeanor.

\section{References and Notes}

1. Lockwood, M., Worboys, G.L. and Kothari, A. 2006. Managing Protected Areas. Earthscan, London, $802 \mathrm{pp}$.

2. Liddle, M. 1997. Recreation Ecology. Chapman \& Hall, London, $639 \mathrm{pp}$.

3. Buckley, R. (ed). 2004. Environmental Impacts of Ecotourism. CAB International, Oxford, $389 \mathrm{pp}$.

4. Buckley, R. 1999. Tools and indicators for managing tourism in parks. Ann. Tourism Res. 26, 207-210.

5. Eagles, P.F.J. and McCool, S.F. 2002. Tourism in National Parks and Protected Areas. CAB International, Wallingford, UK, $320 \mathrm{pp}$.

6. Pigram, J.J. and Jenkins, J.M. 2006. Outdoor Recreation Management (2nd ed). Routledge, Oxford, $329 \mathrm{pp}$

7. Marion, J.L. and Reid, S.E. 2007. Minimising visitor impacts to protected areas: the efficacy of low impact education programs. J. Sustain. Tourism, 15, 5-27.

8. Oliver, S.S., Roggenbuck, J.W. and Watson, A.E. 1985. Education to reduce impacts in forest campgrounds. J. For. 83, 234-236.

9. Jacobi, C. 2003. An Experiment Using Signs to Reduce Visitor-Built Cairns in Acadia National Park. ANP Natural Resource Reports 2002-04. USDI National Park Service, National Park. ANP Na
Bar Harbor, ME, 6 pp.

10. Medio, D., Ormond, R.F.G. and Person, M. 1997. Effect of briefing on rates of damage to corals by SCUBA divers. Biol. Conserv. 79, 91-95.
11. Manfredo, M.J. and Bright, A.D. 1991. A model for assessing the effects of communication on recreationists. J. Leisure Res. 23, 1-20.

12. Cottrell, S.P and Graefe, A.R. 1997. Testing a conceptual framework of responsible environmental behaviour. J. Environ. Educ. 29, 17-27.

13. Petty, R.E. and Cacioppi, J.T. 1986. The elaboration likelihood model of persuasion. Adv. Exp. Soc. Psychol. 19, 123-205.

14. Ajzen, I. 1991. The theory of planned behaviour. Organ. Behav. Hum. Decis. Process. 50, 179-211.

15. We thank Binna Burra Mountain Lodge, its former manager Mr. Linus Bagley, and its interpretive guides for permission and assistance in conducting these experimental tests; Mr. Michael Arthur for assistance with statistical analysis; and Associate Professo Stephen Wearing for assistance in developing best-practice interpretive approaches. We also thank two anonymous referees for encouraging us to extend our discussion.

16. First submitted 31 July 2007. Accepted for publication 9 January 2008.

Carolyn Littlefair is at the NSW National Parks and Wildlife Service. Her address: Visitor and Community Programs, NSW National Parks and Wildlife Service, P.O. Box 1967, Hurstville, NSW 1481, Australia.

E-mail: carolyn.littlefair@environment.nsw.gov.au

Ralf Buckley is at the International Centre for Ecotourism Research, Griffith University. His address: International Centre for Ecotourism Research, Griffith University, Parklands Drive, Gold Coast, Qld 4222, Australia

E-mail: r.buckley@griffith.edu.au 